\title{
Open-Circuit Fault Diagnosis and Maintenance in Multi-Pulse Parallel and Series TRU Topologies
}

\author{
J. Saura, M. Bakkar, and S. Bogarra
}

\begin{abstract}
Transformer Rectifier Units (TRUs) are a reliable way for DC generation in several electric applications. These units are formed by multiple three-phase uncontrolled bridge rectifiers connected according to two main topologies (parallel and series), and fed by a phase-shifting transformer, which can have different configurations. Fault diagnosis of the uncontrolled bridge rectifier diodes is one of the most important concerns on the electronic devices, nonetheless, rectifier units are inherently not protected in front of Open-Circuit $(\mathrm{O} / \mathrm{C})$ faults, which cause malfunction and performance deterioration. In order to solve this drawback, the proposed fault diagnosis method is based on the $\mathrm{O} / \mathrm{C}$ fault signature observed in the DC-link output voltage of TRUs rectifier. It allows detecting the $\mathrm{O} / \mathrm{C}$ diodes of parallel and series TRUs with different phase-shifting transformer configurations and for the most usual fault scenarios. Moreover, it also helps the prediction of diodes that could be exposed to failure after the fault, which provides corrective maintenance for the TRU development. The proposed method is illustrated from MATLAB ${ }^{\mathrm{TM}}$ numerical simulations of a 12-pulse TRU, and is validated with experimental tests.
\end{abstract}

Index Terms--fault diagnosis, open-circuit faults, TRU, threephase uncontrolled bridge rectifier, condition monitoring.

\section{INTRODUCTION}

$\mathrm{P}$ ower electronic converters must satisfy some features such as input harmonic limits, DC-link output voltage ripples, electromagnetic compatibility (EMC) requirement, efficiency and size [1]. This trend will provide some benefits regarding the transmitted power increase, system regulation and smart controllability improvement (e.g., in fault detection and diagnosis).

Disturbances caused by various components in electrical system can inject harmonics into the system and thereby Transformer Rectifier Units (TRUs) are used for improving power quality of the system, increasing the number of pulses per period [2]. Multi-pulse TRUs are used in different applications, take for instance, aerospace industry [3], [4], power distribution systems, railways applications and soft starting of induction motors, [5]-[7]. They are formed by a multiple phase-shifting transformer, which feeds a set of threephase uncontrolled bridge rectifiers connected according to different topologies [2], [8]-[12]. Multi-pulse TRUs can be
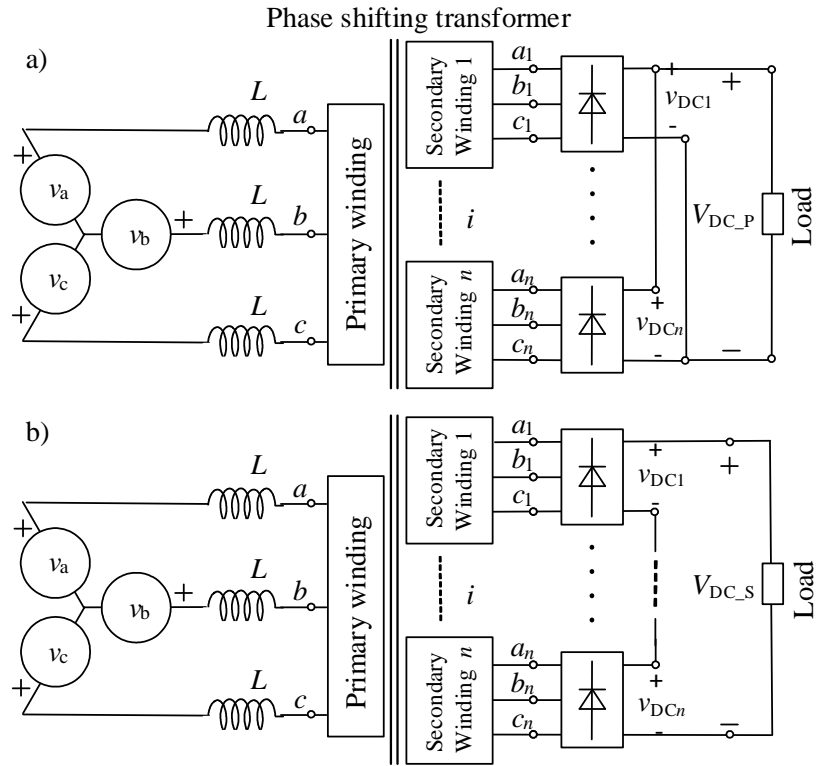

Fig. 1. Multi-pulse TRU: a) Type P. b) Type S.

connected in two possible arrangements: series (Type $S$ ) and parallel (Type P) connection as shown in Fig. 1 [7], [13].

Semiconductors are the backbone of multi-pulse TRUs, which gives more importance to the fault diagnosis especially for these elements. Semiconductor failure can be divided into intrinsic and extrinsic failure depending on different factors. Intrinsic failure related to component design and manufacturing, however, extrinsic failure is related to static or dynamic overload events (electrical, thermal, mechanical or radiative), live cycles, misapplications or accidents [14].

In general, faults in power converters are classified into Short-Circuit (S/C) and Open-Circuit $(\mathrm{O} / \mathrm{C})$ faults. S/C faults can be easily detected due to the high currents involved in the process, however, $\mathrm{O} / \mathrm{C}$ faults are hard to diagnose since large magnitudes of voltage or current are not reached and the system usually continues operating after the O/C fault with worse performance and stress on system components. For this reason, $\mathrm{O} / \mathrm{C}$ faults gains more proportion of the maintenance especially in rectifier units. This is very important in the rectifier of generator systems where voltage control is done based on the output voltage of the rectifier. $\mathrm{O} / \mathrm{C}$ faults in multi-pulse rectifier

J. Saura is with the Dept. of Electrical Engineering, ESEIAAT, UPC, C. Colom 1, 08222 Terrassa, Spain (e-mail: jaume.saura@ upc.edu).

M. Bakkar is PhD student at the Dept. of Electrical Engineering, ESEIAAT, UPC, C. Colom 1, 08222 Terrassa, Spain (e-mail: mostafa.bakkar@upc.edu).

S. Bogarra is with the Dept. of Electrical Engineering, ESEIAAT, UPC, C. Colom 1, 08222 Terrassa, Spain (e-mail: bogarra@ee.upc.edu). 
have consequences not only on the loads [15], [16] but also on the generators [17], [18] and intrinsic maintenance [6], [19]. Different studies focused on the effects of $\mathrm{O} / \mathrm{C}$ faults will be discussed.

The uncontrolled rectifier faults in variable voltage and frequency induction motor drives are studied in [15], an algorithm based on the DC-link output voltage analysis is proposed, in order to classify S/C and O/C faults. Similar approach is presented in [16] where a k-means algorithm based on the Fast Fourier Transform is used to identify all modes of $\mathrm{O} / \mathrm{C}$ faults in three-phase rectifiers. In [18] a comparison between the performance of a five-phase permanent magnet generator coupled to a full-bridge rectifier circuit and an equivalent three-phase permanent magnet system is analyzed under $\mathrm{O} / \mathrm{C}$ phase failures with the same output voltage, output power and machine volume. In [6] the authors focused on the maintenance of some of the faults specially in multi-pulse rectifiers. Likewise, in [19] the explanation of removing one or more diodes from the rectifier and the effects of this on the output DC-link output voltage have been explained.

Several approaches are proposed in the literature for $\mathrm{O} / \mathrm{C}$ fault analysis and diagnosis in multi-pulse TRUs [20]-[24]. Some of the aforementioned studies focus on the $\mathrm{O} / \mathrm{C}$ faults in inverters [23], [24], in this case the fault detection must be fast in order to protect the loads. In addition, artificial intelligent methods (Artificial Neural Network (ANN), Fuzzy Logic Controller (FLC), Discrete Wavelet Transform (DWT), etc.), can be used to identify $\mathrm{O} / \mathrm{C}$ faults in rectifiers, for example in [23] ANN have been used to identify the fault. In this study, large amount of failure data needed in order to train ANN, moreover, the long training time of ANN.

Several fault detection methods have been proposed recently [20]-[22], [25]-[28]. In [20], a detection algorithm based on the fault harmonic signature of the DC-link output voltage is presented for seven different classes of $\mathrm{O} / \mathrm{C}$ faults. In [21] a fault detection method has been presented for an open phase in three-phase diode rectifier including a DC-link. The fault detection is based on the harmonic components ratio of the $1^{\text {st }}$ and $2^{\text {nd }}$ order harmonics to the $6^{\text {th }}$ order harmonics of the DClink output voltage ripples when any one of three phases is opened. In [22] an anti-false-alarm method is proposed, which can detect one or two open switch faults for a doubly fed wind power converter, which is based on the investigation of the characteristics of current signals. The proposed strategy is studied for controlled rectifier in case of three phase and six pulses, and works for uncontrolled rectifier. The idea is based on studying of the diagnosis results and compare it with a threshold value. In [25] a fault diagnosis strategy is proposed for industrial grid connected power converters. The idea is based on the harmonic analysis using Fourier transform, and in order to implement the idea four sensors need to be used to read the current and voltage after the rectifier and after the boost converter. In [26] the same idea was used in a real time application in residential small wind system grid-tied. In [27] a harmonic analysis fault diagnosis using Goerztel algorithm for rectifier in three phase synchronous generator is presented. Only the output DC voltage are measured to identify the faulted
TABLE I

Comparison of different methodologies to multi-pulse fault identification

\begin{tabular}{|c|c|c|c|}
\hline Methodology & Reference & $\begin{array}{c}\text { Time of } \\
\text { detection }\end{array}$ & $\begin{array}{l}\text { Decision } \\
\text { accuracy }\end{array}$ \\
\hline $\begin{array}{l}\text { Harmonic analysis: } \\
\text { - FFT } \\
\text { - energy ratio } \\
\text { - Goertzel }\end{array}$ & $\begin{array}{c}{[16],[20],} \\
{[21],[22],} \\
{[25],[26],} \\
{[27]}\end{array}$ & $>>$ period & $\begin{array}{l}\text { Not in all the } \\
\text { cases } \mathrm{O} / \mathrm{C} \\
\text { diode is } \\
\text { identified }\end{array}$ \\
\hline $\begin{array}{c}\text { Artificial Neural } \\
\text { Network }\end{array}$ & $\begin{array}{c}{[23],[24],} \\
{[28]}\end{array}$ & $\gg$ period & $\begin{array}{l}\text { Need a lot of } \\
\text { training data }\end{array}$ \\
\hline Fault characteristics & [6] & $>$ period & $\begin{array}{l}\text { Identify the } \\
\text { faulty leg }\end{array}$ \\
\hline Interval signatures & $\begin{array}{c}\text { The proposed } \\
\text { strategy }\end{array}$ & A period & $\begin{array}{l}\mathrm{O} / \mathrm{C} \text { faults } \\
\text { identified in } \\
\text { all cases }\end{array}$ \\
\hline
\end{tabular}

phase but not the faulted diode. Comparing the harmonics of the DC voltage before and during the fault to identify if the fault is in the stator or in the rectifier. In [28] a fault diagnosis analysis based on ANN is proposed for voltage source rectifier. The drawback is the need of enough historical failure data to train ANN, the three current vectors are used to train the ANN.

Modern high power semiconductor devices have very high current and voltage ratings, some applications require either series or parallel connections of devices to obtain the full output voltage and output current of the equipment. For high power bridges, there are several diodes connected in order to achieve the required power, and this is represented as one diode. Typical examples are HVDC (High Voltage Direct Current) transmissions and high current rectifiers for Aluminum smelters. As seen in Table I, the aforementioned studies are proposed for detection of individual diode, but not all the methodologies allow identifying every $\mathrm{O} / \mathrm{C}$ fault diodes. In addition, these methods need more than a period in order to measure and to process the obtained data, and then the decision is taking. In addition, for AI methods many failure data needed in order to train the controller. However, using the proposed algorithm, maximum one period is needed to give a decision. Moreover, the methodologies shown in Table I are proposed for six pulses rectifier, however the proposed strategy demonstrated for 6,12 and 18 pulses.

As shown in the literature, most of the fault diagnoses methods are based on harmonic analysis of the DC-link output voltage, which need high calculation procedures, which cause imprecise decisions in some situations. Moreover, more than one period is needed to take the appropriate decision.

This paper presents a new method to detect the O/C diodes, based on the fault signature of the DC-link output voltage. Each fault produces a different effect on the DC output voltage according to the number of faulty diode; the DC-link output voltage signature presents several minimums and its analysis gives the information for detecting $\mathrm{O} / \mathrm{C}$ diodes of multi-pulse TRUs with high fault diagnosis precision. The main benefits of the proposed algorithm are the ability to detect the exact $\mathrm{O} / \mathrm{C}$ fault diode using minimum numbers of sensors, in addition the decision of the algorithm is updated at the end of each period, which makes this study faster than the other aforementioned studies. 


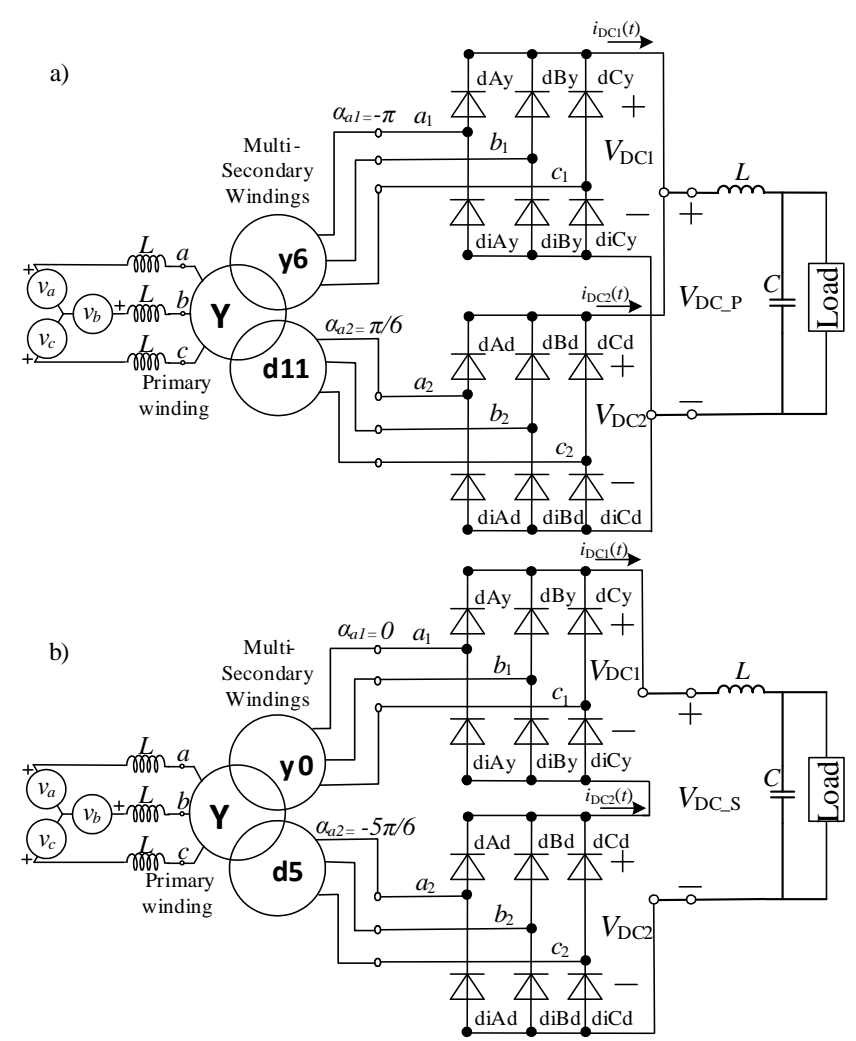

Fig. 2. 12-pulse TRU: a) Type $\mathrm{P}$ with Yy6d11 b) Type $\mathrm{S}$ with Yy0d5 transformer configuration.

TABLE II

Convention of Assign Diodes Names

\begin{tabular}{|c|c|c|c|}
\hline Diode & Phases & Connection & Example \\
\cline { 1 - 3 } Direct $\rightarrow \mathrm{d}$ & \multirow{2}{*}{$\mathrm{A}, \mathrm{B}, \mathrm{C}$} & $\mathrm{Y} \rightarrow \mathrm{y}$ & $\mathrm{dCy}$ \\
\cline { 1 - 1 } \cline { 4 - 4 } Inverse $\rightarrow \mathrm{di}$ & & $\Delta \rightarrow \mathrm{d}$ & $\mathrm{diBd}$ \\
\hline
\end{tabular}

\section{Multi-PulSe TRANSFORMER Rectifier Units}

In the last decades, multi-pulse TRUs became the basis for DC-generation of different electric applications [3], [4], [6]. Their operation depends on three-phase uncontrolled bridge rectifiers fed by a phase-shifting transformer and either connected in parallel and series topologies (see Fig. 1(a) and Fig. 1(b), respectively).

The main benefits of uncontrolled rectifier systems using multi-winding transformer are that for any load the global power factor is practically enhancing.

According to Fig. 1, the next equation describes the DC-link output voltage for the continuous conduction mode for each bridge that composes TRU.

$v_{D C i}(t)=\max \left\{v_{a i}(t), v_{b i}(t), v_{c i}(t)\right\}-\min \left\{v_{a i}(t), v_{b i}(t), v_{c i}(t)\right\}$.

where $v_{\mathrm{a} i}, v_{\mathrm{b} i}$, and $v_{\mathrm{c} i}$ are the $a b c$ phase voltages. The value of DC-link output voltage values $v_{\mathrm{DC}_{-} \mathrm{P}}(t)$ and $v_{\mathrm{DC} \_} \mathrm{s}(t)$ will vary according to the connection topology Type $\mathrm{P}$ or Type S. Equations (2) and (3) describe the DC-link output voltage on the output of the bridge for both connections, respectively.

$$
\begin{gathered}
v_{\mathrm{DC} \_\mathrm{P}}(t)=\max \left(v_{\mathrm{DC} 1}(t), \ldots . v_{\mathrm{DC} i}(t), \ldots v_{\mathrm{DC} n}(t)\right) . \quad 1 \leq i \leq n \\
v_{\mathrm{DC} \_\mathrm{S}}(t)=\sum_{i=1}^{n} v_{\mathrm{DC} i}(t) .
\end{gathered}
$$

The calculation of the average value for each bridge in
TABLE III

\begin{tabular}{|c|c|c|c|c|}
\hline \multicolumn{3}{|c|}{ Connection group C.E.I } & $\begin{array}{c}\text { Primary }\left(\mathbf{n}_{1}\right) \\
\text { Secondary }\left(\mathbf{n}_{2}\right)\end{array}$ & $\begin{array}{c}\text { Initial } \\
\text { angle }\end{array}$ \\
\hline \multirow{4}{*}{$\frac{\left.\left.\{\}^{a}\right\}^{b}\right\}^{c}}{Y}$} & \multirow{2}{*}{$\mathrm{y}$} & $\left.0\left\{\xi^{a_{1}}\right\}^{b_{1}}\right\}^{c_{1}}$ & $\frac{n_{1}}{n_{2}}$ & 0 \\
\hline & & $6 a_{1}^{k}$ & $\frac{n_{1}}{n_{2}}$ & $\pi$ \\
\hline & \multirow{2}{*}{ d } & 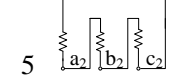 & $\sqrt{3} \frac{n_{1}}{n_{3}}$ & $-\frac{5 \pi}{6}$ \\
\hline & & $11 \xi^{a_{2} b^{2}}$ & $\sqrt{3} \frac{n_{1}}{n_{3}}$ & $\frac{\pi}{6}$ \\
\hline \multirow{4}{*}{$\frac{\xi^{a} \xi^{b}}{D}$} & \multirow{2}{*}{$\mathrm{y}$} & $5\left\{\mathrm{a}_{1} \xi_{0} \mathrm{~b}_{1} \mathrm{c}_{1}\right.$ & $\frac{1}{\sqrt{3}} \frac{n_{1}}{n_{2}}$ & $-\frac{5 \pi}{6}$ \\
\hline & & $\left.\left.11\}^{a_{1}}\right\}^{b_{1}}\right\}^{c_{1}}$ & $\frac{1}{\sqrt{3}} \frac{n_{1}}{n_{2}}$ & $\frac{\pi}{6}$ \\
\hline & \multirow{2}{*}{$\mathrm{d}$} & $\left.0 \xi^{a_{2}} \xi^{b_{2}}\right\}^{c_{2}}$ & $\frac{n_{1}}{n_{3}}$ & 0 \\
\hline & & $6\left\lfloor\mathrm{a}_{2}\left\lfloor\mathrm{~b}_{2}\left\lfloor\mathrm{k}_{\mathrm{c}_{2}}\right.\right.\right.$ & $\frac{n_{1}}{n_{3}}$ & $\pi$ \\
\hline
\end{tabular}

Transformer Configurations in Clock Reference

balanced condition for the three-phase voltages feeding the primary windings of parallel and series connection can be obtained using (4) and (5) respectively:

$$
\begin{aligned}
& V_{\mathrm{DC} \_\mathrm{P}}=2 \frac{n \cdot p \cdot V}{\pi} \sin \left(\frac{\pi}{n \cdot p}\right)-\sum_{i=1}^{n} \frac{3}{\pi} \omega L_{\mathrm{si}} i_{\mathrm{DCi}} \\
& V_{\mathrm{DC} \_\mathrm{S}}=2 \frac{n \cdot p \cdot V}{\pi} \sin \left(\frac{\pi}{p}\right)-\sum_{i=1}^{n} \frac{3}{\pi} \omega L_{\mathrm{si}} i_{\mathrm{DCi}},
\end{aligned}
$$

where $p$ is the number of pulses, $n$ is the number of bridges, $L_{\mathrm{si}}$ is the leakage inductance seen by each bridge, $i_{\mathrm{DCi}} \mathrm{DC}$ current of each bridge and $V$ is the grid peak phase voltage.

The analyzed case shown in Fig. 2 corresponds to $p=12$ and $n=2$. For Type $\mathrm{P}$, the DC-link output voltage is the maximum DC voltage of both bridges. However, for Type S, DC-link output voltage is the addition of the DC-link output voltage of the two bridges. The nomenclature used in Fig. 2, for the names of the diodes in the rectifier is explained in Table II.

Phase-shifting transformers have a single primary and multiple isolated secondary windings, which are appropriately connected to obtain the leading and lagging voltages with respect to primary winding voltages. Table III shows different transformer configurations of 12-pulse TRUs using clock reference. Each secondary of the transformer has different initial angle according to the connection configuration of the transformer. For example, the second row of Table III shows one connection (Yy6) of the secondary and the tertiary of the transformer (Yd11) is shown in row 4. That means that the initial angle of the two secondary windings of the Yy6d11 transformer are $\pi$ and $\pi / 6$ respectively (fifth column in Table III). For this transformer configuration (Yy6d11), the instantaneous voltages are defined by following equations: 


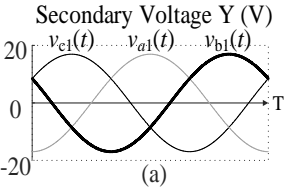

Tertiary Voltage $\Delta(\mathrm{V})$

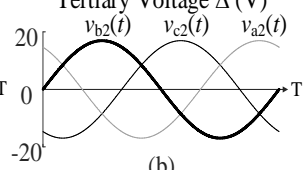

(b)

$\left(i_{\mathrm{DC} 1}\right)$ Currents of phase $\mathrm{Y}(\mathrm{A})\left(i_{\mathrm{DC} 2}\right)$ Currents of phase $\Delta(\mathrm{A}) \quad$ Primary Currents $(\mathrm{A})$

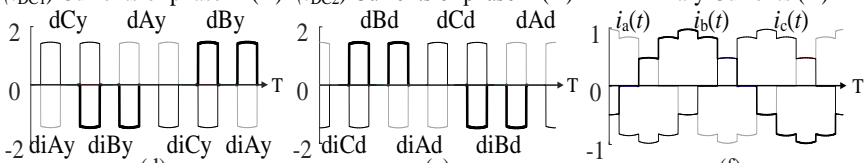

(d)

(e)

Fig. 3. Y and $\Delta$ voltages and currents, primary currents and DC-link output voltage for Type $\mathrm{P}$ topology with Yy6d11 transformer configuration

$$
\begin{aligned}
& \text { Primary }\left\{\begin{array}{l}
v_{a}(t)=\sqrt{2} V_{\mathrm{a}} \cos (\omega t+0) \quad(\omega=2 \pi f), \\
v_{b}(t)=\sqrt{2} V_{\mathrm{b}} \cos (\omega t-2 \pi / 3), \\
v_{c}(t)=\sqrt{2} V_{\mathrm{c}} \cos (\omega t+2 \pi / 3) .
\end{array}\right. \\
& \text { Secondary }\left\{\begin{array}{l}
v_{a 1}(t)=\sqrt{2} \frac{n_{1}}{n_{2}} V_{\mathrm{a}} \cos (\omega t+\pi), \\
v_{b 1}(t)=\sqrt{2} \frac{n_{1}}{n_{2}} V_{\mathrm{b}} \cos (\omega t+\pi-2 \pi / 3), \\
v_{c 1}(t)=\sqrt{2} \frac{n_{1}}{n_{2}} V_{\mathrm{c}} \cos (\omega t+\pi+2 \pi / 3) .
\end{array}\right. \\
& \text { Tertiary }\left\{\begin{array}{l}
v_{a 2}(t)=\sqrt{2} \frac{n_{1}}{n_{3}} V_{\mathrm{a}} \cos (\omega t+\pi / 6), \\
v_{b 2}(t)=\sqrt{2} \frac{n_{1}}{n_{3}} V_{\mathrm{b}} \cos (\omega t+\pi / 6-2 \pi / 3), \\
v_{c 2}(t)=\sqrt{2} \frac{n_{1}}{n_{2}} V_{\mathrm{c}} \cos (\omega t+\pi / 6+2 \pi / 3) .
\end{array}\right.
\end{aligned}
$$

Fig. 2 illustrates the most installed TRU that is the 12-pulse TRU connected in parallel (Fig. 2(a)) and series (Fig. 2(b)). They are fed through Yy6d11 and Yy0d5, respectively. For different TRUs configurations, the same methodology can be used considering the variation in the initial angle.

Fig. 3 and Fig. 4 show a period of the simulated voltages and currents obtained from MATLAB code, for Type P and Type $S$ respectively. Fig. 3(a) and Fig. 3(d) show the secondary $a b c$ voltages $\left(v_{\mathrm{a} 1}(t), v_{\mathrm{b} 1}(t), v_{\mathrm{c} 1}(t)\right)$ and the DC current of the first bridge, where $i_{\mathrm{DC} 1}(t)$ marked in Fig. 2 is the positive part of the current related to the direct diodes. Fig. 3(b) and Fig. 3(e) show the tertiary $a b c$ voltages $\left(v_{\mathrm{a} 2}(t), v_{\mathrm{b} 2}(t), v_{\mathrm{c} 2}(t)\right)$, and $i_{\mathrm{DC} 2}(t)$ marked in Fig. 2 is the positive part of the current related to the direct diodes. Fig. 3(c) and Fig. 3(f) shows the DC voltage at the output of the two bridges $\left(v_{\mathrm{DC} 1}(t), v_{\mathrm{DC} 2}(t)\right)$, and DC-link output voltage $\left(v_{\mathrm{DC} \_\mathrm{P}}(t)\right)$, obtained from $(2)$, and $a b c$ primary currents of the transformer $\left(i_{\mathrm{a}}(t), i_{\mathrm{b}}(t), i_{\mathrm{c}}(t)\right)$. Fig. 4 have the same distribution as Fig. 3, but for the series connection. Considering that the DC-link output voltage $\left(v_{\mathrm{DC} \_} \mathrm{s}(t)\right)$ is obtained from $(3)$.

\section{OPen Diode Faults In Multi-Pulse Transformer RECTIFIER UNITS}

Faults in rectifier unit have a direct effect on the signature of the DC-link output voltage. These signatures can be analyzed in order to identify the faulty diode. A methodology has been developed in order to identify the fault signature, and recognize the faulty diodes.
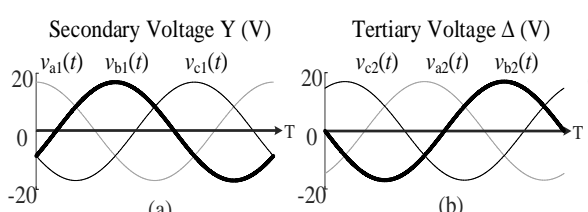

(b)

DC voltage with Yy0d5 (V)

$\left(i_{\mathrm{DC} 1}\right)$ Currents of phase $\mathrm{Y}(\mathrm{A}) \quad\left(i_{\mathrm{DC} 2}\right)$ Currents of phase $\Delta(\mathrm{A})$

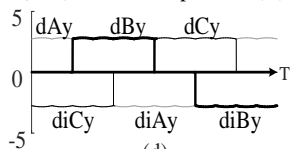

(d)

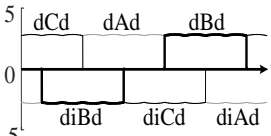

(e) $v_{\mathrm{DC} \_} \mathrm{S}(t)$ $v_{\mathrm{DC} 1}(t) v_{\mathrm{DC} 2}(t)$

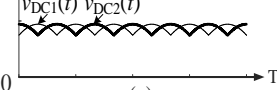

(c)

Primary Currents (A)

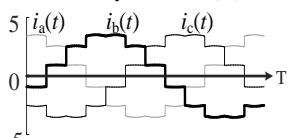

(f)

Fig. 4. $\mathrm{Y}$ and $\Delta$ voltages and currents, primary currents and DC-link output voltage for Type $\mathrm{S}$ topology with Yy0d5 transformer configuration

The DC-link output voltage of the rectifier resulting from different sets of faulty diodes has different numbers of minimums. According to the number of faulty diodes, the number of minimums is changing, due to loss of diode firing coordination. During fault, the time of conduction for one of the diodes will increase and that will cause a minimum value in rectifier voltage. As seen in Fig. 5, the difference between healthy and faulty condition is the appearance of the depth minimums, which are called global minimums. For healthy conditions there are only expected minimums, there are called local minimums (Fig. 5(a) and Fig. 5(b) for healthy condition). At the contrary, in case of one faulty diode in parallel connection, two global minimums appear with voltage restore between them (1/12 of period for each in the case of 12 pulses), at the same time whereby the diode was conducting before the $\mathrm{O} / \mathrm{C}$ fault. As shown in Fig. 5(b), every diode of the bridge conducting $120^{\circ}$, only one time in a period. However, the current of phase Y of Fig. 5(a) shows that, every diode conducts $1 / 12$ of the period twice per period (for example dAy diode is shown in gray color), and during the un-conducting time of dAy of the secondary conducts $\mathrm{dCd}$ of the tertiary (thin black color). Which will produce the two global minimums when dAy is O/C faulted, as seen in the second row of Fig. 5(a). Nevertheless, for series connection, in fault condition appear one deeper and wider global minimum than in the case of parallel connection, as seen in the second row of Fig. 5(b), because the period of conduction for every diode is larger and without voltage restore (1/3 of period for 12 pulses).

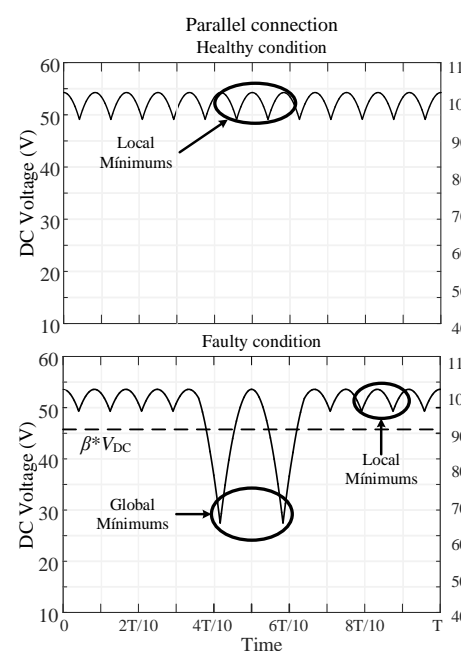

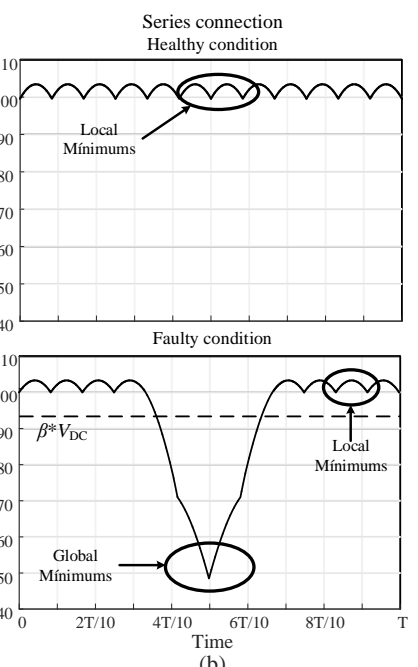

(b)

Fig. 5. minimums in case of healthy and faulty condition for (a) dAy with Type P (Yy6d11) and (b) diAy with Type S (Yy0d5) connections 


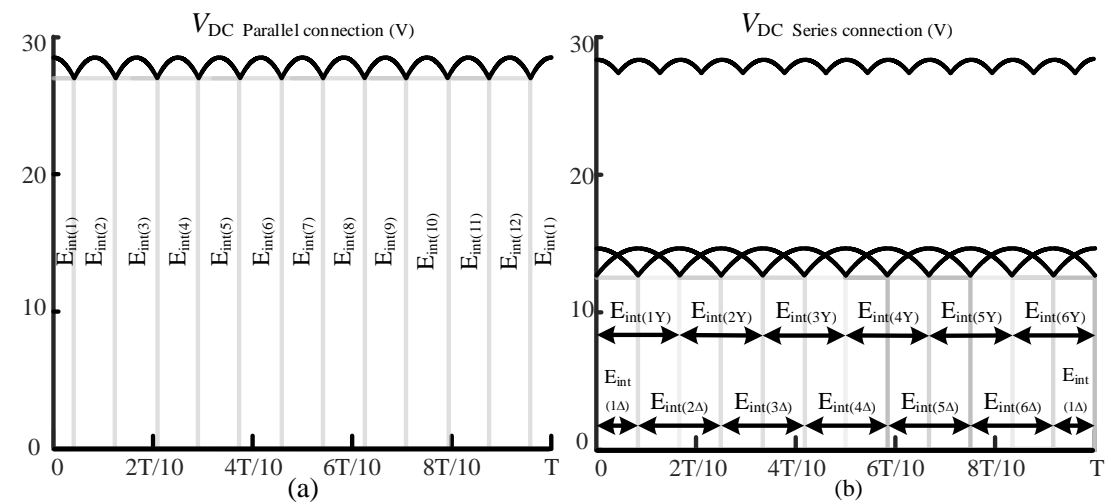

Fig. 6. $v_{\mathrm{DC}}(\omega t)$ expected on balanced and continuous conduction mode (CCM) conditions, and interval classification for Type $\mathrm{P}$ with Yy6d11 and Type $\mathrm{S}$ with Yy0d5 connections

Each fault produces a different effect on the DC output voltage according to the number of faulty diodes. In case of parallel connection, if there are two global minimums, then the bridge has only one faulty diode. Whereas if there are more than two global minimums, then the conclusion is there are more than one faulty diode, for other combination of faulty diodes the figures are different but the conclusion is the same. In case of 4 faulty diodes, a big drop in voltage can be observed for longer time than in the case of a lower number of faulty diodes. In order to know which diodes are in $\mathrm{O} / \mathrm{C}$, a good strategy was to divide the period into intervals and observed to analyze if the voltage into each of them is less than the fixed limit of the $\mathrm{V}_{\mathrm{DC}}$, as seen in Fig. 5 (dashed line).

For series connection there are four diodes conducting at the same time, for example in Fig. 4(d) and Fig. 4(e) at $t=T / 2$ conducting (dBy, diAy of the secondary, and dAd, diCd of the tertiary), instead of the two diodes that are conducting in the case of parallel connection, because only is conducting the secondary or the tertiary. Therefore, the analysis of the global minimum does not give the same conclusion. In this case, it is preferable to study $\mathrm{V}_{\mathrm{DC} 1}$ and $\mathrm{V}_{\mathrm{DC} 2}$ separately. The measured values and the average value calculated using (4) and (5) are compared in order to identify the $\mathrm{O} / \mathrm{C}$ diodes as is explained in Section IV.

\section{PRocedure For Open Diode FAult Detection In MULTI-PULSE TRANSFORMER RECTIFIER UNITS}

Control Monitoring (CM) has already been proven a cost effective means of enhancing reliability and improving customer service in power equipment. The proposed fault diagnosis algorithm can be a perfect tool in order to establish these objectives for rectifiers. In this section, the theoretical methodology and implementation of the proposed fault detection algorithm for series and parallel p-pulse rectifier will be discussed. The main aim of the proposed algorithm is to reduce the time and cost of maintenance and prevents more severe faults occurrence. The proposed algorithm is able to be used offline by uploading the measurement signals to the algorithm; moreover, it can be used online by updating its decision at the end of each period.

In order to identify the faulted diode, a period of rectifier DC output voltage is measured, $\left(v_{\mathrm{DC}}(1: N)\right.$, where $N$ is the number of DC voltage values acquired per period). The period started at $(0)^{\circ}$ and maximum value of phase $a$ of TRU primary voltage.
This angle could be obtained using a single phase PLL, in order to be less susceptible to voltage disturbances.

In the case of parallel connection, the period is divided into intervals according to number of pulses, in case of 12-pulse rectifier, the period divided into 12 intervals, one interval for each pulse. The number of points in every interval is:

$$
N_{\text {int }}=\frac{N}{p},
$$

The following equations are used to calculate minimum $V_{\mathrm{DC}}$ for each interval in case of parallel connection (see Fig. 6(a)):

$$
\begin{aligned}
& V_{\min (1)}=\min \left\{v_{\mathrm{DC}}\left(1: \frac{N_{\text {int }}}{2}\right), v_{\mathrm{DC}}\left(N-\frac{N_{\text {int }}}{2}: N\right)\right\},(2 \leq k \leq p) \\
& V_{\min (k)}=\min \left\{v_{\mathrm{DC}}\left(\frac{(k-1) \cdot N_{\text {int }}}{2}+1: \frac{(2 k-1) \cdot N_{\text {int }}}{2}\right)\right\} .
\end{aligned}
$$

For series connection, Y secondary winding (see Fig. 6(b)):

$$
V_{\mathrm{Y} \min (k)}=\min \left\{v_{\mathrm{DC}}\left((k-1) \cdot N_{\mathrm{int}}+1: k \cdot N_{\mathrm{int}}\right)\right\},(1 \leq k \leq p / 2) .
$$

For series connection, $\Delta$ secondary winding (see Fig. 6(b)):

$$
\begin{aligned}
& V_{\Delta \min (1)}=\min \left\{v_{\mathrm{DC}}\left(1: \frac{N_{\text {int }}}{2}\right), v_{\mathrm{DC}}\left(N-\frac{N_{\text {int }}}{2}: N\right)\right\},(2 \leq k \leq p / 2) \\
& V_{\Delta \min (k)}=\min \left\{v_{\mathrm{DC}}\left(\frac{(k-1) \cdot N_{\text {int }}}{2}+1: \frac{(2 k-1) \cdot N_{\text {int }}}{2}\right)\right\} .
\end{aligned}
$$

The diode conduction in each interval depends on the transformer configuration shown in Table III. After intervals identification corresponding to the transformer configuration, the faulty diodes can be identified according to the minimum DC voltage calculated in each interval, applying the algorithm shown in Fig. 7. These minimums are compared with the boundary value $(\beta)$ calculated according to the average value between local and global minimums (13), as shown in Fig. 7.

$$
\frac{V_{\mathrm{DCminLocal}}}{V_{\mathrm{DC}}}>\beta>\frac{V_{\mathrm{DC} \text { minGlobal }}}{V_{\mathrm{DC}}},(0.977>\beta>0.876)
$$

The algorithm shown in Fig. 7 for detection of the faulty diodes can be explained as follows:

1- Read $v_{\mathrm{DC}}(1: N)$ for one period $\mathrm{T}$.

2- Identify the minimum values during the interval, Using equation (10) or (11) and (12).

3 - Compare obtained minimum values to $\beta^{*} V_{\mathrm{DC}}$ of the original average value of the output DC voltage, if the minimum value is below $\beta^{*} V_{\mathrm{DC}}$ which means a diode is 


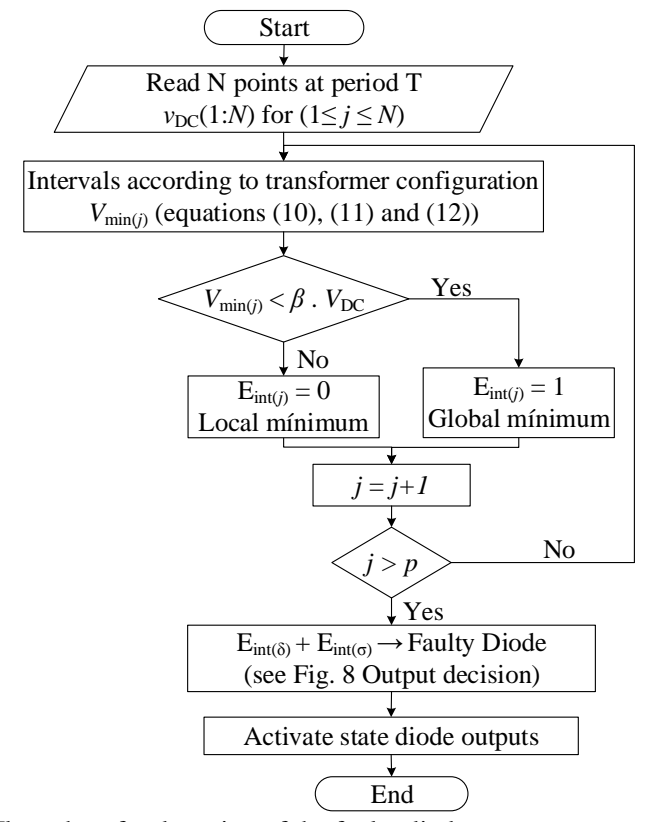

Fig. 7. Flow chart for detection of the faulty diodes

$\mathrm{O} / \mathrm{C}$, and index $\mathrm{E}_{\text {int }(\mathrm{j})}$ is equal to 1 , if not then $\mathrm{E}_{\mathrm{int}(\mathrm{j})}$ is equal to 0 , which means there is no fault.

4- Increment $j$ by one and compare it to $p$. if $j$ is less than $p$ then returns again to calculate the minimum of the next interval, if yes continue with the following step.

5- Every faulty diode is identified through two global minimums according to the configuration, for example in the case of the Yy6d11, the table that relates the state identification with the faulty diodes is shown in Fig. 8 (a), which shows an example of faulty diode identification in case of Yy6d11 transformer configuration. After interval determination, the following steps need to be done in order to identify the faulty diode according to number of global minimums detected as shown in Fig. 8(a), and depending on transformer configurations.

6- Activate state diode outputs.

Table IV and Table V in Fig. 8(a) and Fig. 8(b) respectively show the index values for Type $\mathrm{P}$ and Type $\mathrm{S}$ with Yy6d11 and Yy0d5, respectively. As seen, the order of operation for each diode is changed according to the TRU configuration, wherefore the value of index will be altering. The proposed algorithm is tested by simulation and experimentally in the lab with 12 pulses TRU to verify the applicability of the idea. However, for different types of multi-pulse TRU the proposed algorithm is applicable also using the same steps shown in Fig. 7.

In case of two diodes have been $\mathrm{O} / \mathrm{C}$ in different legs, as seen in Fig. 8, one diode from the opposite leg will not conduct because of the corresponding $\mathrm{O} / \mathrm{C}$ diodes. That means, that diodes sustained more current than other diodes and it needs to be replaced also. So, for example, if diodes diBy and diCy (black color in Fig. 8) are $\mathrm{O} / \mathrm{C}$ in that case it is preferable to change diode dAy (gray color in Fig. 8) with the two faulty diodes, not for a corrective maintenance but for a predictive maintenance, because this diode conducts at the same time that the others.

Similar behavior can be noticed when one or more diodes are $\mathrm{O} / \mathrm{C}$, the rest of the diodes in the rectifier circuit will sustain more time conduction current, furthermore some of them faces more energy than the others.

The main difference between parallel and series algorithms is the need for additional measurement signal. In case of parallel connection, DC-link output voltage $\left(V_{\mathrm{DC}}\right)$ and phase voltage $\left(v_{\mathrm{a}}\right)$ are used as input signals to the fault identification algorithm. However, for series connection using only $V_{\mathrm{DC}}$ and $v_{\mathrm{a}}$ will not give accurate results in all fault cases. Mainly this is due to different voltage between $V_{\mathrm{DC}}$ and DC-link output voltage of Y $\left(V_{\mathrm{DC} 1}\right)$ or $\Delta\left(V_{\mathrm{DC} 2}\right)$ sides. For parallel connection, regardless the number of the bridges connected in parallel, using only two sensors the $\mathrm{O} / \mathrm{C}$ fault can be identified. For series connection, the DC output of each bridge need to be measured with phase a voltage, because in this case two diodes per bridge are conducting at the same time. In order to conclude, for parallel connection all voltages are the same. However, in case of series connection, in addition to $v_{\mathrm{a}}$, DC-link output voltages of each transformer side ( $V_{\mathrm{DC} 1}$ and $V_{\mathrm{DC} 2}$ ) need to be measured.

During continuous conduction mode (CCM), the algorithm is able to give the correct decision with $L C$ filter and different types of loads, by measuring $V_{\mathrm{DC}}$ at the output of each bridge and phase a voltage.

Similar idea can be used for 18 pulse TRUs, in order to identify the $\mathrm{O} / \mathrm{C}$ faults in each bridges. In this case, the system consists of: TRU with three secondary windings with $20^{\circ}$ phase shift between each of them, and three bridges connected to each

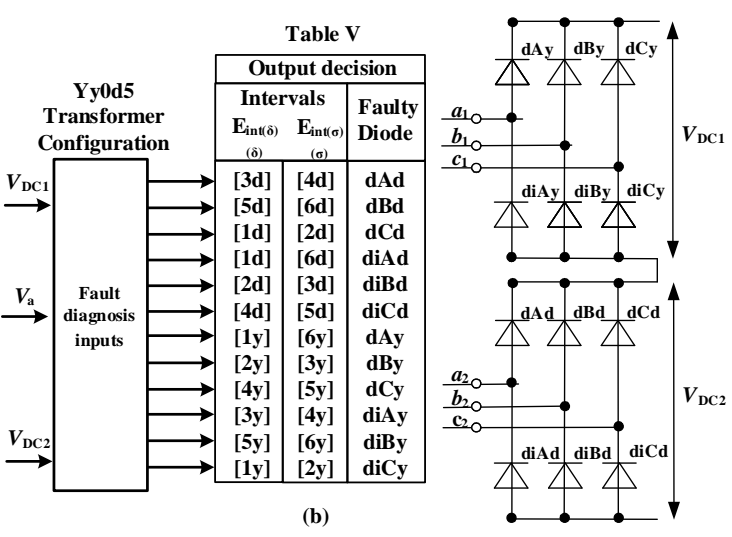

Fig. 8. Corresponding global minimums intervals associated with O/C Fault (a) Type P connection, (b) Type S connection 


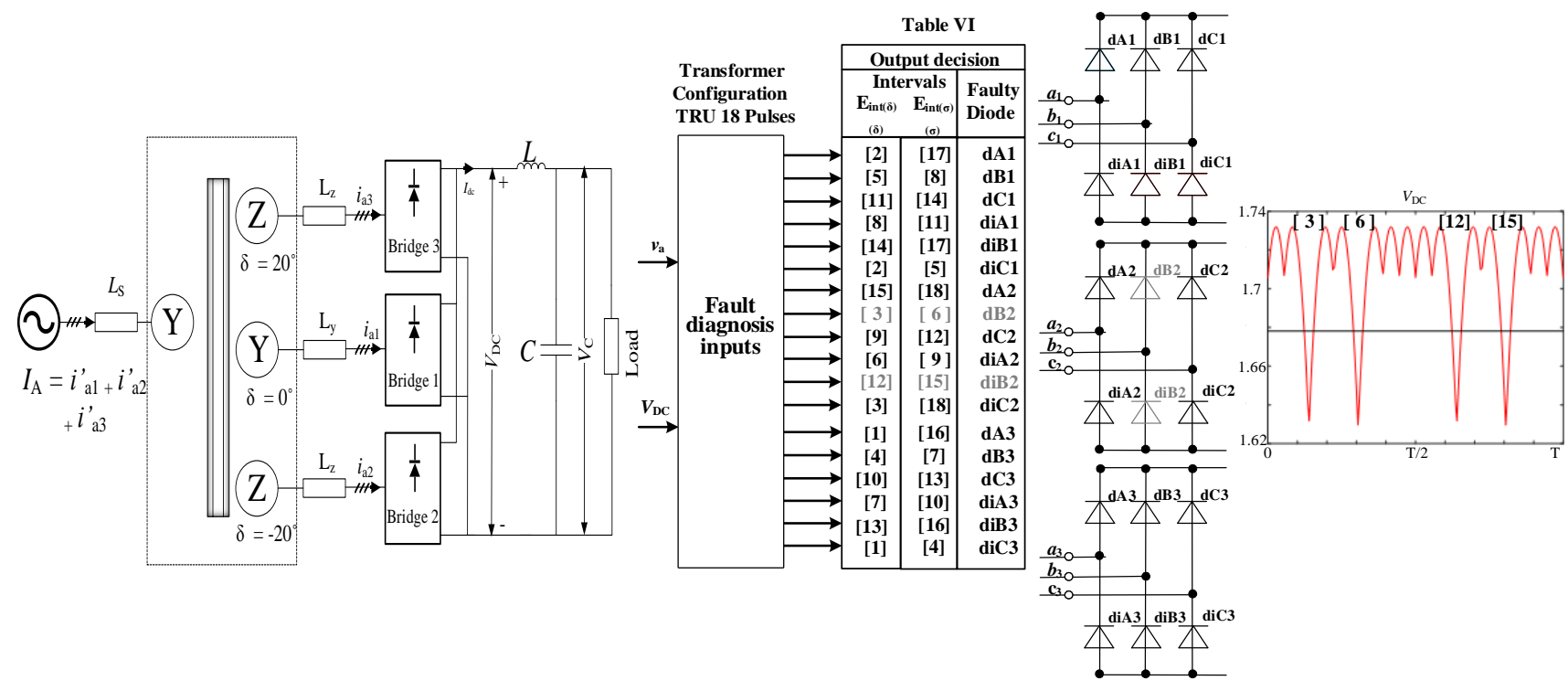

Fig. 9 Corresponding global minimums intervals associated with O/C Fault for 18 pulse TRUs for Type P connection with Yy6d11 transformer connection

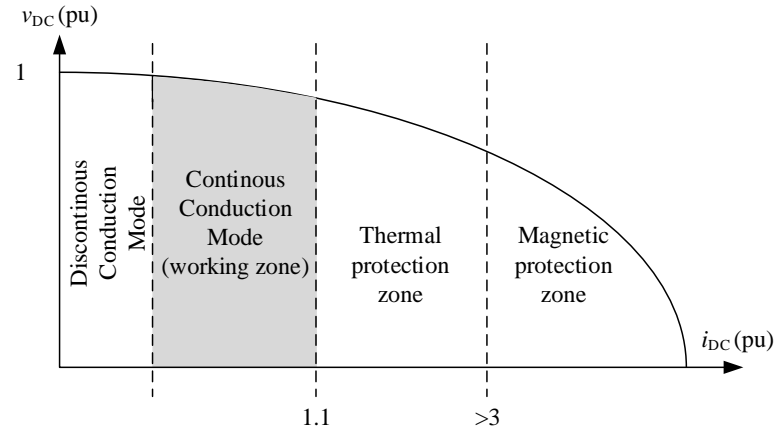

Fig. 10 Different region on 'DC voltage from the load DC current' curve

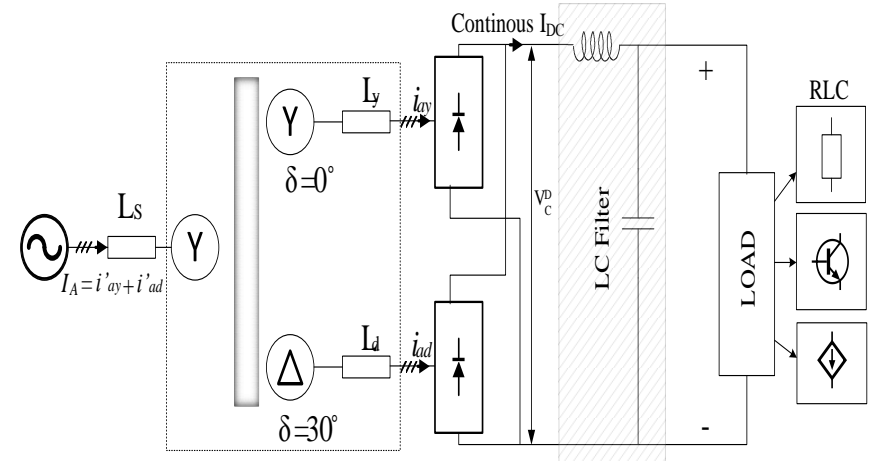

Fig. 11 Twelve pulses Type $\mathrm{P}$ with different types of loads and $L C$ filter secondary. The same idea used to construct Table IV and $\mathrm{V}$ are used to build Table VI, as shown in Fig. 9. If dB2 and diB2 are in $\mathrm{O} / \mathrm{C}$ fault, the maximums intervals 3 and 6 for $\mathrm{dB} 2$, also intervals 12 and 15 for diB2. In these intervals global minimums will appear.

The proposed algorithm also identifies S/C faults with protective fuses. Because fuses normally protect S/C faults, which will convert $\mathrm{S} / \mathrm{C}$ to $\mathrm{O} / \mathrm{C}$ faults.

In addition, during CCM the algorithm is able to give the correct decision with $L C$ filter and different types of loads. Fig. 10 shows the working zone is the CCM, which depends on the configuration of every rectifier and load. If the DC current is continuous, the proposed strategy works with different types of loads as shown in Fig. 11, by measuring $V_{\mathrm{DC}}$ and $v_{\mathrm{a}}$. If the load impedance is too high, that means the current reduction will be large, and $i_{\mathrm{DC}}$ will be discontinuous, so in this case the algorithm will not work properly.

\section{RESULtS}

A. Theoretical Results: Fig. 12 and Fig. 13 show Y and $\Delta$ winding voltages, currents and DC-link output voltage for the same $\mathrm{O} / \mathrm{C}$ diode with different transformer configuration, in case of series and parallel connection, respectively. Different types of transformer configuration are tested, in order to show the behavior changes in voltages and currents of $\mathrm{Y}$ and $\Delta$ winding connections for series and parallel topologies. Fig. 12 shows the same $\mathrm{O} / \mathrm{C}$ fault (diAd) for Type $\mathrm{S}$ with different TRUs clock configuration and Fig. 13 shows the same O/C fault (dBy) for Type P with different TRUs clock configuration. As seen the conducting intervals will change as the clock configuration changes, nevertheless, the same behavior is recognized, and the proposed algorithm can identify the O/C faults in both cases.

B. Graphical User Interface (GUI): In order to make the algorithm easier and handful for CM procedure, a graphical user interface has been developed, in order to satisfy the idea. The aim of GUI is to be used offline as tool for all possibilities of transformer configurations with any type of fault and for both possible topologies. This program can be a useful tool in case of maintenance procedure for Multi-Pulse Rectifier Units. The GUI showed in Fig. 14 consists of two main parts, which are the inputs (parameters, configuration of the system, and signal upload) and the outputs (decision of the algorithm and plots).

The inputs are: "1" connections (Type P or Type S), "2" line to line voltages $\left(V_{\mathrm{L} 1}\right)$ and $\left(V_{\mathrm{L} 2}\right)$, frequency, load resistance, "3" frequency, "4" transformer configuration and " 5 " faulted diodes. Another possibility is to upload a measurement signal of the $V_{\mathrm{DC}}$, in this case, previous inputs will be halted, in this case "10" which is upload plots and "4" which is the transformer configuration will be the only inputs. 

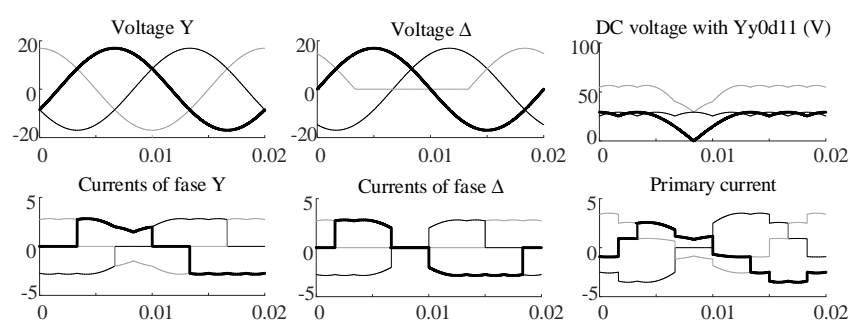

(a) diAd with Yy0d11 transformer configuration
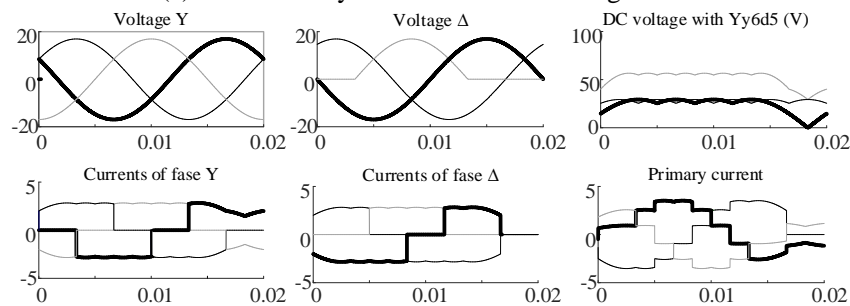

(b) diAd with Yy6d5 transformer configuration

Fig. $12 \mathrm{Y}$ and $\Delta$ winding voltages, currents and DC-link output voltage for the same $\mathrm{O} / \mathrm{C}$ diode (diAd) with different transformer configuration for Type $\mathrm{S}$ connection
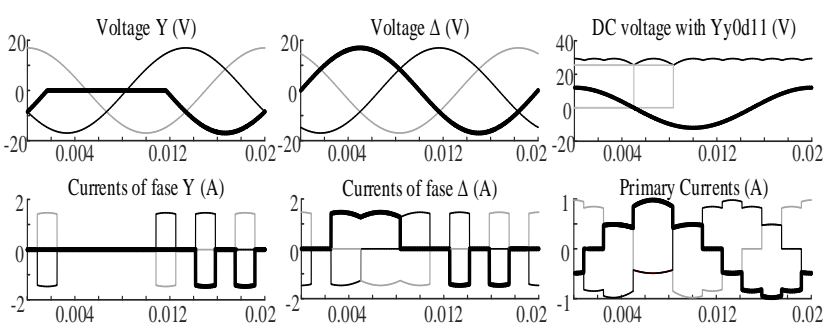

(a) dBy with Yy0d11 transformer configuration
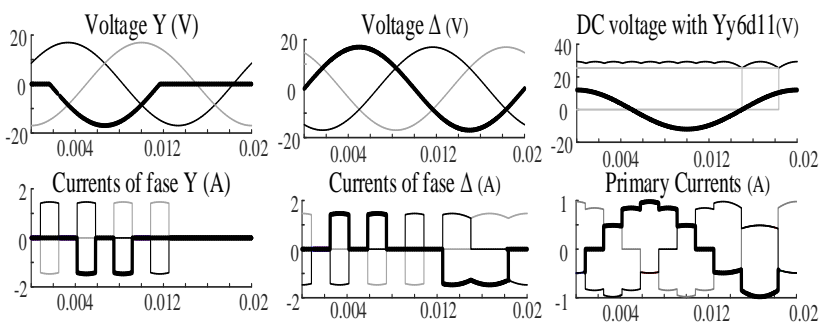

(b) dBy with Yy6d11 transformer configuration

Fig. $13 \mathrm{Y}$ and $\Delta$ winding voltages, currents and DC-link output voltage for the same $\mathrm{O} / \mathrm{C}$ diode $(\mathrm{dBy})$ with different transformer configuration for Type $\mathrm{P}$ connection

The outputs are: " 6 " decision and fault indicators (black and gray stands for healthy and faulty diode, respectively), , "7" plots for primary current, current at $\mathrm{Y}$ connection, current at $\Delta$ connection and DC-link output voltage, also, choose harmonics to be represented and " 8 " run the algorithm.

\section{Experimental Results:}

\section{1) Offline Study}

In this case GUI has been used to identify the $\mathrm{O} / \mathrm{C}$ faults using " 10 " to upload experimental data for one period to the algorithm which will be the only input for the algorithm in this case, with the transformer connection " 4 ", and the bridge connection (Type P or Type S) "1". This is a good tool for CM to show the reliability of the algorithm.

\section{2) Online Study}

In order to verify the theoretical results, an experimental setup is built in the laboratory with the parameters shown in Table VII. Fig. 15 shows LAB experimental setup. Three windings transformer $8000 \mathrm{VA}, 50 / 60 \mathrm{~Hz}$ is used in validation,

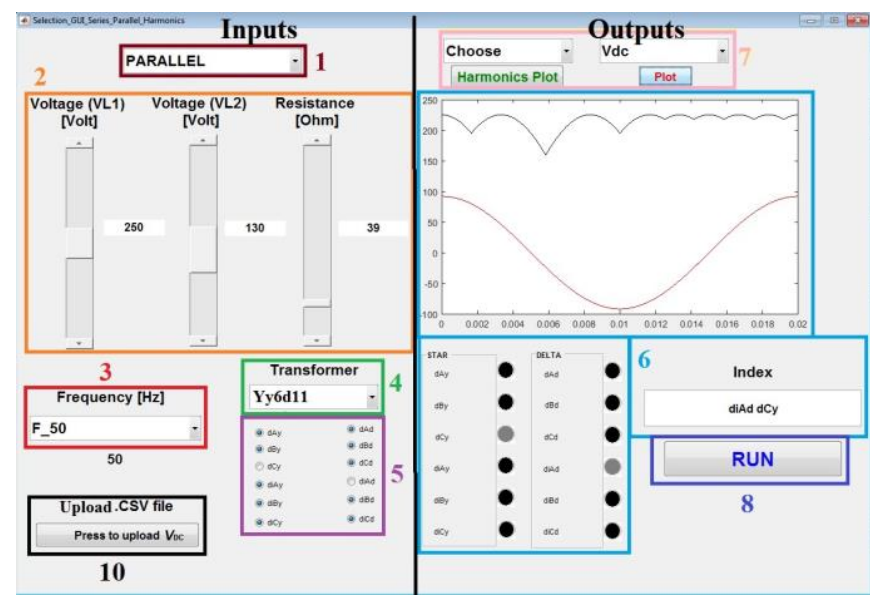

Fig. 14 GUI inputs and outputs

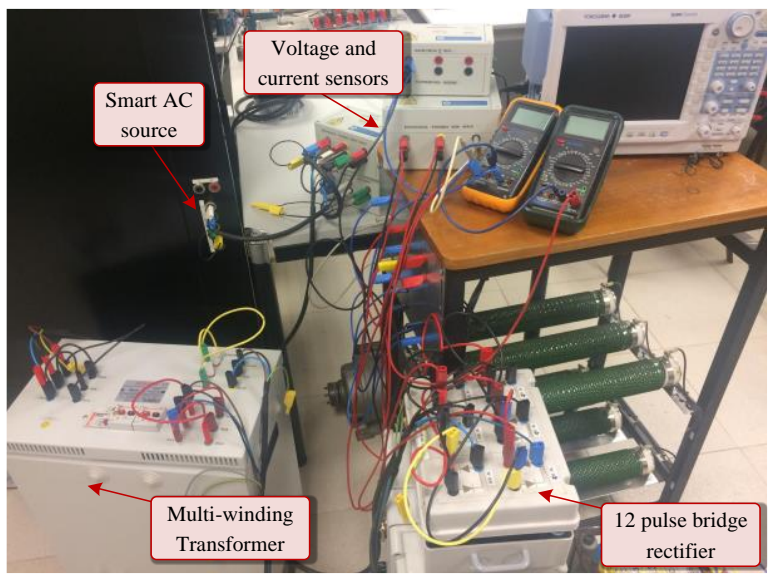

Fig. 15 Experimental setup
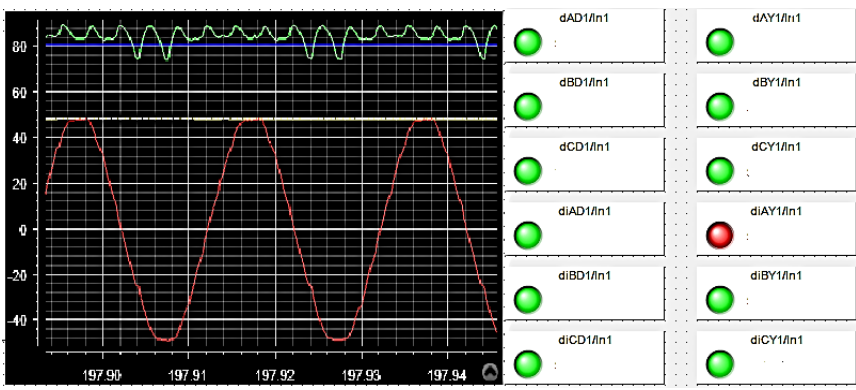

Fig. 16 Online detection using dSPACE

with three-phase supply. The transformer has the flexibility to be connected either star or delta in the three windings. The online study is based on using dSPACE 1104 in order to implement the proposed algorithms using MATLAB ${ }^{\mathrm{TM}}$ Simulink. During one period 120 samples are read, and at the end of each period the algorithm updates its decision. Fig. 16 shows the online detection of diAy for Type P with Dy $11 \mathrm{~d} 0$ configuration, as seen the algorithm is able to identify the global minimums in each period in order to update its decision.

In order to verify the ability of the algorithm to identify the faulty diode with different types of connections, Fig. 17(a) compares between experimental and theoretical results for Type $\mathrm{P}$ with $\mathrm{O} / \mathrm{C}$ fault at dCd with Yy6d5 configuration. Fig. 17(b) compares between experimental and theoretical results for Type $\mathrm{P}$ with $\mathrm{O} / \mathrm{C}$ fault at dAd with Dy11d6 configuration respectively. In addition, Fig. 17(c) and Fig. 17(d) compare between experimental and theoretical results for Type $\mathrm{S}$ with 
TABLE VII

System parameters

\begin{tabular}{|c|c|}
\hline \multicolumn{2}{|c|}{ Transformer Parameters } \\
\hline Power & $8000 \mathrm{VA}$ \\
\hline Input voltage & $230 \sim 400 \mathrm{~V}$ \\
\hline Output voltage & $\mathrm{S} 1 / 230 \mathrm{~V}(\mathrm{D})-400 \mathrm{~V}(\mathrm{Y})$ “4 KVA” \\
\hline Frequency & $50 / 60 \mathrm{~Hz}$ \\
\hline Connection group & (D/Y) d/y d/y \\
\hline \multicolumn{2}{|c|}{ Three-phase Pacific Smart SourceTM model 345-AMX } \\
\hline Power & $4.5-\mathrm{kVA}$ \\
\hline Input voltage & maximum line-to-line voltage of 468 V \\
\hline \multicolumn{2}{|c|}{ Bridge } \\
\hline Diodes & SemikronTM model SKKD 46/16 \\
\hline \multicolumn{2}{|c|}{ Loads and $\boldsymbol{L C}$ filter } \\
\hline Resistor & $10 \sim 42 \Omega$ \\
\hline Capacitor & $4 \sim 120 \mathrm{uF}$ \\
\hline Inductor & $10 \mathrm{mH}$ \\
\hline
\end{tabular}

$\mathrm{O} / \mathrm{C}$ fault at $\mathrm{dBy}$ with $\mathrm{YyOd} 5$ configuration and at $\mathrm{dCy}$ and diCy with Yy6d5 configuration, respectively. As shown in Fig. 17, the local minimum between the bridge connected to $\mathrm{Y}$ and changed to the bridge connected to $\Delta$ is different from the local minimum between bridges connected to $\Delta$ and $\mathrm{Y}$ due to the change in the leakage inductance difference [29]. However, the global minimum is less than these changes and the proposed algorithm is able to identify the local minimums in both experimental and theoretical, as shown in (13). Fig. 17 shows that the results which prove the good behaviour of the proposed algorithm to identify the faulty diode correctly. The influence of PF in DC voltage is shown in Fig. 18(a), (b) and (c), where several capacitors are used in order to check the proposed strategy in CCM. Furthermore, the proposed strategy is tested
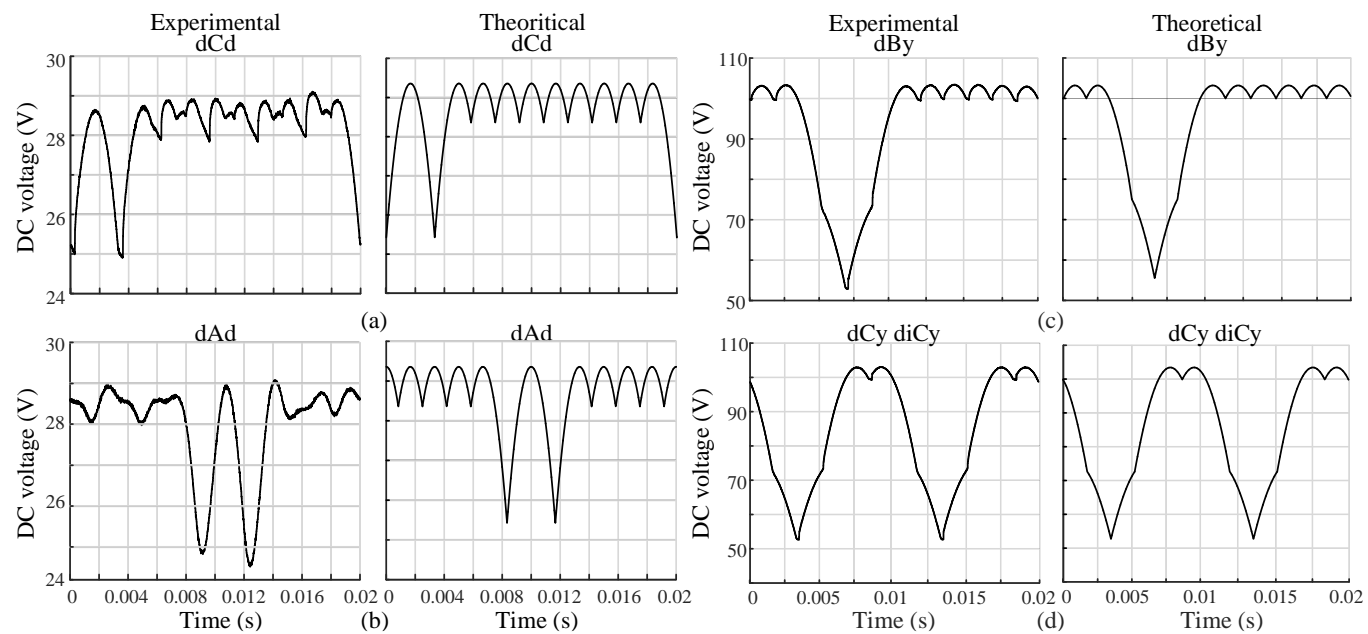

Fig. 17 DC voltage of 12 pulse TRU in case of (a) Type P connection with fault at dCd with Yy6d5 configuration, (b) Type P connection with fault at dAd with Dy11d6 configuration, (c) Type S connection with fault at dBy with Yy0d5 configuration (d) Type S connection with fault at dCy and diCy with Yy6d5 configuration

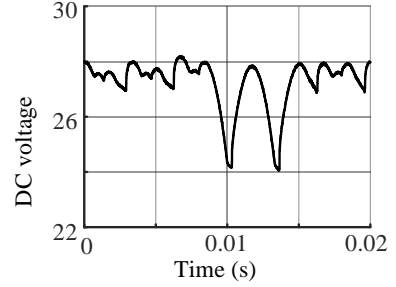

(a)

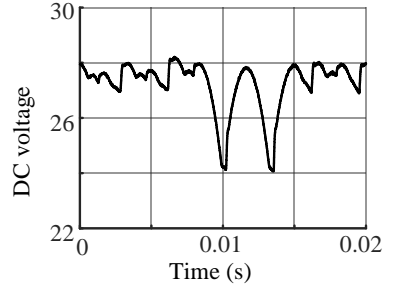

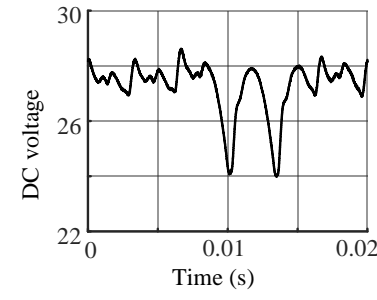

(c)

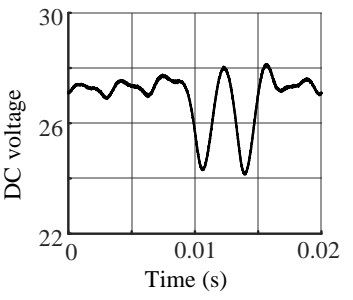

(d)

Fig. 18 DC voltage of 12 pulse TRU for Type $\mathrm{P}$ with different $\mathrm{P}$.F. a) $\mathrm{C}=4 \mathrm{uF}$, b) $\mathrm{C}=8 \mathrm{uF}, \mathrm{C}$ ) $\mathrm{C}=30 \mathrm{uF}$ and d) $\mathrm{C}=30 \mathrm{uF}, \mathrm{L}=9.78 \mathrm{mH}$ 
Moreover, the simplicity of the proposed algorithm is a key point, as only two signals are needed in order to identify the faulted device. Using the proposed algorithm will gain many benefit to not only corrective maintenance but also related to predictive maintenance.

For the experimental results, the impedances of the secondary and tertiary windings of the transformer presents unbalance impedances, which cause small asymmetry in the DC output voltage of the bridges. Nevertheless, the proposed algorithm can identify the $\mathrm{O} / \mathrm{C}$ fault in these cases.

In the future, these signatures can be used to identify the faulty diodes using artificial intelligent techniques. In addition, the possibility to combine more than one technique for fault detection (global minimum, harmonics, continuity ... etc.) in one algorithm, can be an excellent solution for more reliable system.

\section{ACKNOWLEDGMENT}

The work presented in this paper is part of the research project: Estabilidad de redes mvdc integrando tecnologias de energias renovables, almacenamiento de energia y convertidores de fuente de impedancia, (RTI2018-095720-BC33), funded by the Ministerio de ciencia, innovación y universidades and European Union.

\section{REFERENCES}

B. Singh, S. Gairola, B. N. Singh, A. Chandra and K. Al-Haddad, "Multipulse AC-DC Converters for Improving Power Quality: A Review," in IEEE Transactions on Power Electronics, vol. 23, no. 1, pp. 260-281, Jan. 2008.

[2] B. Singh, G. K. Kasal and S. Gairola, "Power Quality Improvement in Conventional Electronic Load Controller for an Isolated Power Generation," in IEEE Transactions on Energy Conversion, vol. 23, no. 3, pp. 764-773, Sept. 2008.

[3] A. Baghramian, A. Cross and A. Forsyth, "Interactions within heterogeneous systems of uncontrolled rectifiers for aircraft electrical power systems," in IET Electrical Systems in Transportation, vol. 1, no. 1, pp. 49-60, March 2011.

[4] A. Cross, A. Baghramian and A. Forsyth, "Approximate, average, dynamic models of uncontrolled rectifiers for aircraft applications," in IET Power Electronics, vol. 2, no. 4, pp. 398-409, July 2009.

[5] Yii-Shen Tzeng, Nanming Chen and Ruay-Nan Wu, "Modes of operation in parallel-connected 12-pulse uncontrolled bridge rectifiers without an interphase transformer," in IEEE Transactions on Industrial Electronics, vol. 44, no. 3, pp. 344-355, June 1997.

[6] C. Shu, L. Wei, D. Rong-Jun and C. Te-Fang, "Fault Diagnosis and Fault-Tolerant Control Scheme for Open-Circuit Faults in ThreeStepped Bridge Converters," in IEEE Transactions on Power Electronics, vol. 32, no. 3, pp. 2203-2214, March 2017.

[7] H. Akagi, "Large static converters for industry and utility applications," in Proceedings of the IEEE, vol. 89, no. 6, pp. 976-983, June 2001.

[8] B. Singh and S. Gairola, "A 28-pulse AC-DC converter for line current harmonic reduction," in IET Power Electronics, vol. 1, no. 2, pp. 287-295, June 2008.

[9] A. D. Gerlando, G. M. Foglia, M. F. Iacchetti and R. Perini, "Comprehensive steady-state analytical model of a three-phase diode rectifier connected to a constant DC voltage source," in IET Power Electronics, vol. 6, no. 9, pp. 1927-1938, November 2013.

[10] B. Singh and S. Gairola, "Pulse Doubling in 18-Pulse AC-DC Converters," 2007 7th International Conference on Power Electronics and Drive Systems, Bangkok, 2007, pp. 533-539.

[11] B. Singh and S. Gairola, "A 44-Pulse AC-DC Converter Based on Hybrid of Multiphase and Phase Shifting Techniques," 2008 Joint International Conference on Power System Technology and IEEE Power India Conference, New Delhi, 2008, pp. 1-6.

[12] Sewan Choi, Junyong Oh, Kiyong Kim and Junggoo Cho, "A new 24-pulse diode rectifier for high voltage and high power applications," 30th Annual IEEE Power Electronics Specialists
Conference. Record. (Cat. No.99CH36321), Charleston, SC, USA, 1999, pp. 169-174.

[13] S. Ebrahimi, N. Amiri, L. Wang and J. Jatskevich, "Efficient Modeling of Six-Phase PM Synchronous Machine-Rectifier Systems in State-Variable-Based Simulation Programs," in IEEE Transactions on Energy Conversion, vol. 33, no. 3, pp. 1557-1570, Sept. 2018.

[14] A. Stevenson, Power converter handbook: Theory, design, application, 1st ed., Bailieboro, Canada, UYK Technologies, 2004.

[15] G. Mahmoud, M. Masoud and I. El-Arabawy, "Rectifier Faults In Variable Voltage Variable Frequency Induction Motor Drives," 2007 IEEE International Electric Machines \& Drives Conference, Antalya, 2007, pp. 1125-1130.

[16] M. Rahnama, A. Vahedi, A. M. Alikhani, N. Takorabet and B. Fazelbakhsheshi, "A novel diode open circuit fault detection in three phase rectifier based on k-means method," 2018 IEEE International Conference on Industrial Technology (ICIT), Lyon, 2018, pp. 600605.

[17] S. Jordan, C. D. Manolopoulos and J. M. Apsley, "Winding Configurations for Five-Phase Synchronous Generators With Diode Rectifiers," in IEEE Transactions on Industrial Electronics, vol. 63, no. 1, pp. 517-525, Jan. 2016.

[18] N. E. A. M. Hassanain and J. E. Fletcher, "Steady-state performance assessment of three- and five-phase permanent magnet generators connected to a diode bridge rectifier under open-circuit faults," in IET Renewable Power Generation, vol. 4, no. 5, pp. 420-427, September 2010.

[19] G. Seguier, Power Electronics Converters. AC-DC conversion, 4th ed. Mexico: McGraw-Hill, 1986.

[20] M. Rahiminejad, C. Diduch, M. Stevenson and L. Chang, "Opencircuit fault diagnosis in 3-phase uncontrolled rectifiers," $20123 \mathrm{rd}$ IEEE International Symposium on Power Electronics for Distributed Generation Systems (PEDG), Aalborg, 2012, pp. 254-259.

[21] J. Lee, S. Baek, K. Cho, H. Kim and Jaeho-Choi, "Fault detection of three phase diode rectifier based on harmonic ratio of DC-link voltage ripples," 2017 IEEE 12th International Conference on Power Electronics and Drive Systems (PEDS), Honolulu, HI, 2017, pp. 386391.

[22] P. Duan, K. Xie, L. Zhang and X. Rong, "Open-switch fault diagnosis and system reconfiguration of doubly fed wind power converter used in a microgrid," in IEEE Transactions on Power Electronics, vol. 26, no. 3, pp. 816-821, March 2011.

[23] P. Han et al., "Fault Diagnosis and System Reconfiguration Strategy of a Single-Phase Three-Level Neutral-Point-Clamped Cascaded Inverter," in IEEE Transactions on Industry Applications, vol. 55, no. 4, pp. 3863-3876, July-Aug. 2019.

[24] Z. Huang, Z. Wang and H. Zhang, "A Diagnosis Algorithm for Multiple Open-Circuited Faults of Microgrid Inverters Based on Main Fault Component Analysis," in IEEE Transactions on Energy Conversion, vol. 33, no. 3, pp. 925-937, Sept. 2018.

[25] T. Kamel, Y. Biletskiy and L. Chang, "Fault Diagnoses for Industrial Grid-Connected Converters in the Power Distribution Systems," in IEEE Transactions on Industrial Electronics, vol. 62, no. 10, pp. 6496-6507, Oct. 2015.

[26] T. Kamel, Y. Biletskiy and L. Chang, "Real-Time Diagnosis for Open-Circuited and Unbalance Faults in Electronic Converters Connected to Residential Wind Systems," in IEEE Transactions on Industrial Electronics, vol. 63, no. 3, pp. 1781-1792, March 2016.

[27] R. Sabir, D. Rosato, S. Hartmann and C. Gühmann, "Detection and Localization of Electrical Faults in a Three Phase Synchronous Generator with Rectifier," 2019 International Conference on Electrical Drives \& Power Electronics (EDPE), The High Tatras, Slovakia, 2019, pp. 18-23.

[28] T. Shi, Y. He, T. Wang and B. Li, "Open Switch Fault Diagnosis Method for PWM Voltage Source Rectifier Based on Deep Learning Approach," in IEEE Access, vol. 7, pp. 66595-66608, 2019.

[29] B. Wu, High-Power Converters and AC Drives, 2nd ed. Hoboken, New Jersey: IEEE Press., 2006. 